\title{
Transcriptional regulatory control of Histoplasma capsulatum for biofilms formation
}

PITANGUI, N.S. ${ }^{1}$; SARDI, J.C.O. ${ }^{1}$, GOMES, P.C. ${ }^{1}$; VARANI, A.M. ${ }^{2}$; FERNANDES, C.C. ${ }^{2}$; RODRÍGUEZ-ARELLANES, G. ${ }^{3}$; TAYLOR, M.L. ${ }^{3}$; MENDESGIANNINI, M.J.S. ${ }^{1} ;$ FUSCO-ALMEIDA, A.M. ${ }^{1}$

1. Universidade Estadual Paulista (UNESP), Faculdade de Ciências Farmacêuticas, Araraquara, Brazil

2. Universidade Estadual Paulista (UNESP), Faculdade de Ciências Agrárias e Veterinárias, Jaboticabal, Brazil.

3. Universidad Nacional Autónoma de México (UNAM), Facultad de Medicina, México DF, Mexico.

Key words: Histoplasma capsulatum, biofilms, transcriptomic analysis.

\section{INTRODUCTION}

Histoplasma capsulatum variety capsulatum is responsible for a human systemic mycosis that constitutes a major health problem in the world, named histoplasmosis (Rodríguez-Cerdeira et al., 2012). Some microorganisms attached to biological and nonbiological surfaces are able to form biofilms, which are dynamic communities enclosed in an exopolymeric matrix (Costerton et al., 1995). Biofilm formation by $H$. capsulatum was described by our group as a new virulence factor (Pitangui et al., 2012; Pitangui et al., 2016).

\section{OBJECTIVE}

Based on the importance of biofilms and its persistence on host tissues and cell surfaces, the present study was designed to investigate the transcriptional regulation of H. capsulatum biofilms and planktonic cells.

\section{METHODS}

H. capsulatum biofilms and planktonic cultures were developed in vitro using EH315 (bat clinical strain) and 60I (human clinical strain) strains. Complete sequencing of the transcribed regions was performed by HiSeq Illumina platform including construction of cDNA libraries, cluster generation and sequencing (Fig. 1). The data obtained were analysed by software Seqyclean 1.9.9 - Next Generation Sequencing Cleaning and "de novo" assembly was performed from the sequencing data using CLC Genomics Workbench 6.5.1. software

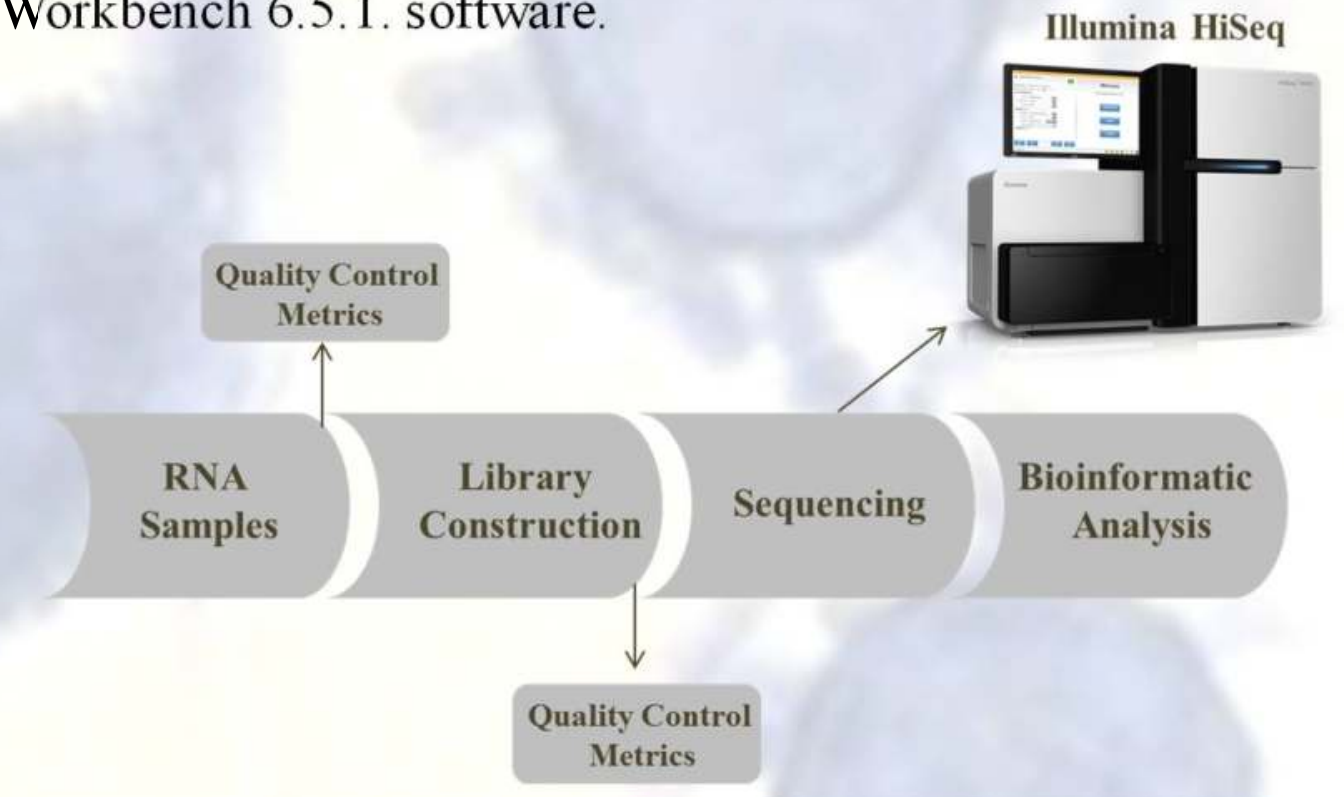

Fig. 1. Experimental workflow for RNA-Seq using the Illumina HiSeq 2500. Basic steps of Next Generation Sequencing (NGS) method which comprises sample/library preparation, cluster amplification, DNA sequencing, image analysis/base calling, read alignment, and variant discovery.

\section{RESULTS}

The results obtained show that the conformation of yeasts in biofilms induces a negative regulation of the transcriptional processes resulting from repressed expression of most genes ( $\approx 80 \%$ down-regulated) (Fig. 2). In addition, the identification of the transcripts products with significantly altered expression in biofilms reveals that proteins with hydrolase activity (cell wall-associated hydrolase) and an elongation factor (EF 1-alpha) appear to play fundamental roles in structuring this pathogen in complex three-dimensional networks which characterize biofilms (Fig. 3).

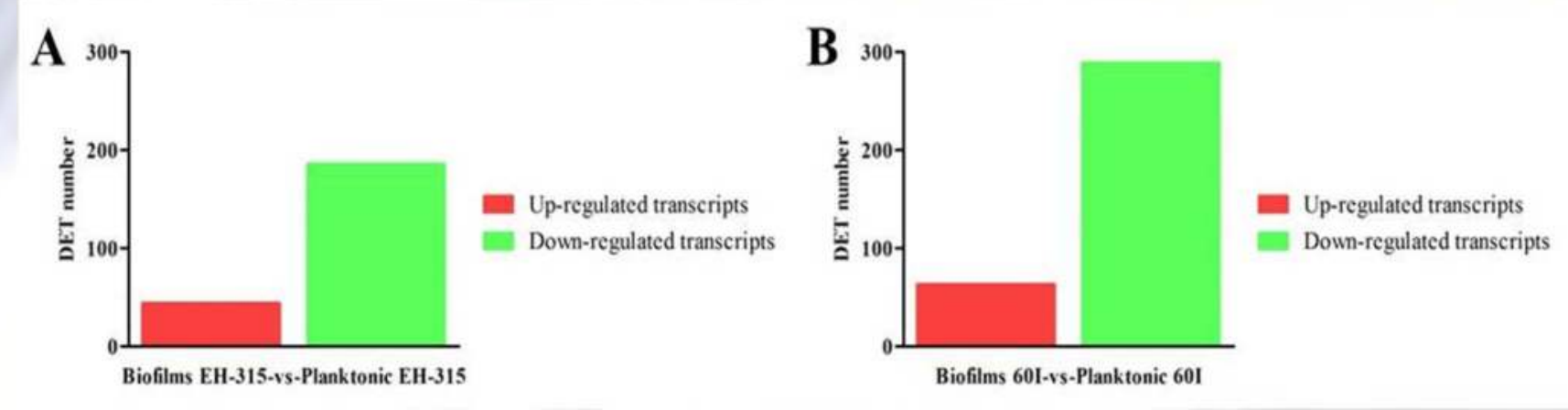

Fig. 2. Transcriptional regulatory control of $H$. capsulatum. Number of up-regulated and repressed (down-regulated) transcripts, obtained by a transcriptomic approach. Differential transcriptomic profile of the strain EH-315 in biofilms and planktonic growth (A), and 60I strain in biofilms and planktonic growth (B). DET - Differentially expressed transcripts.

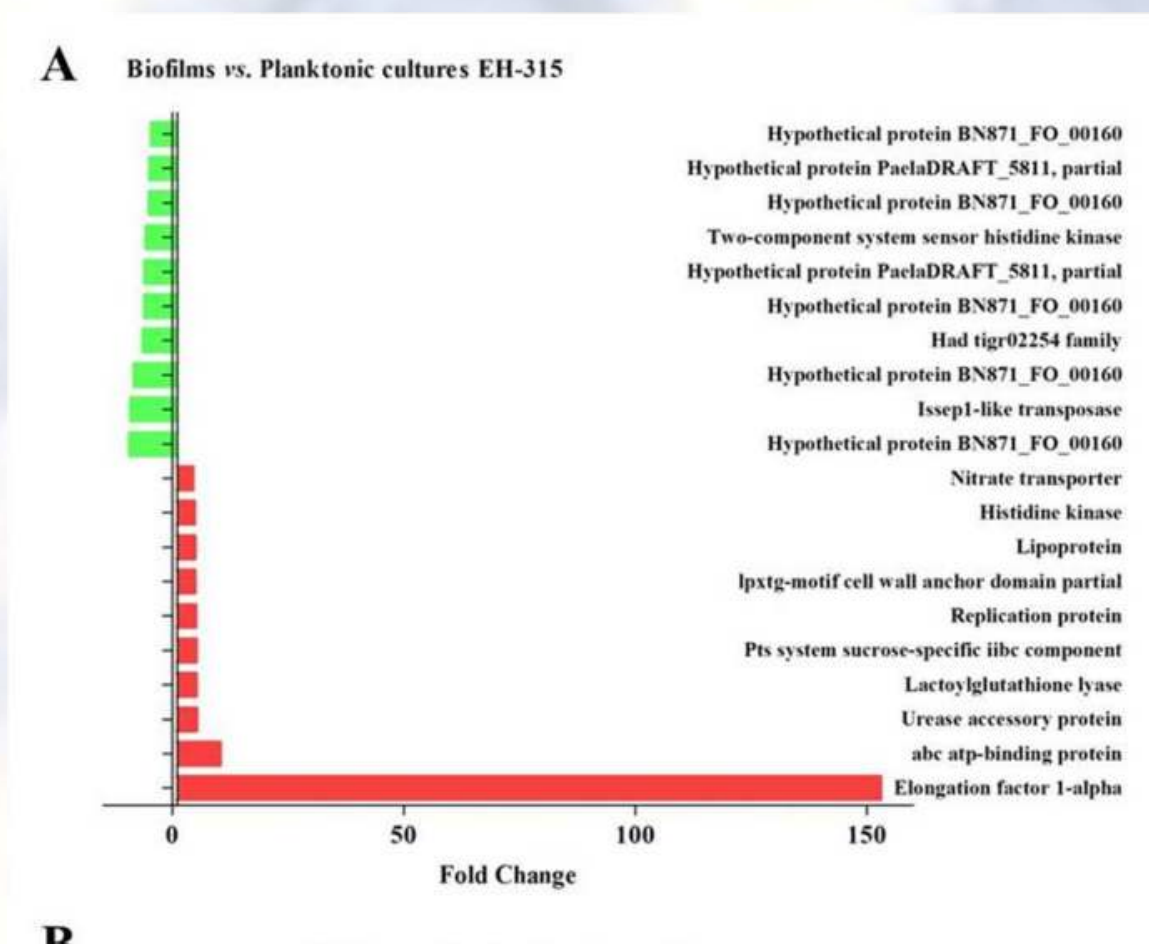

B

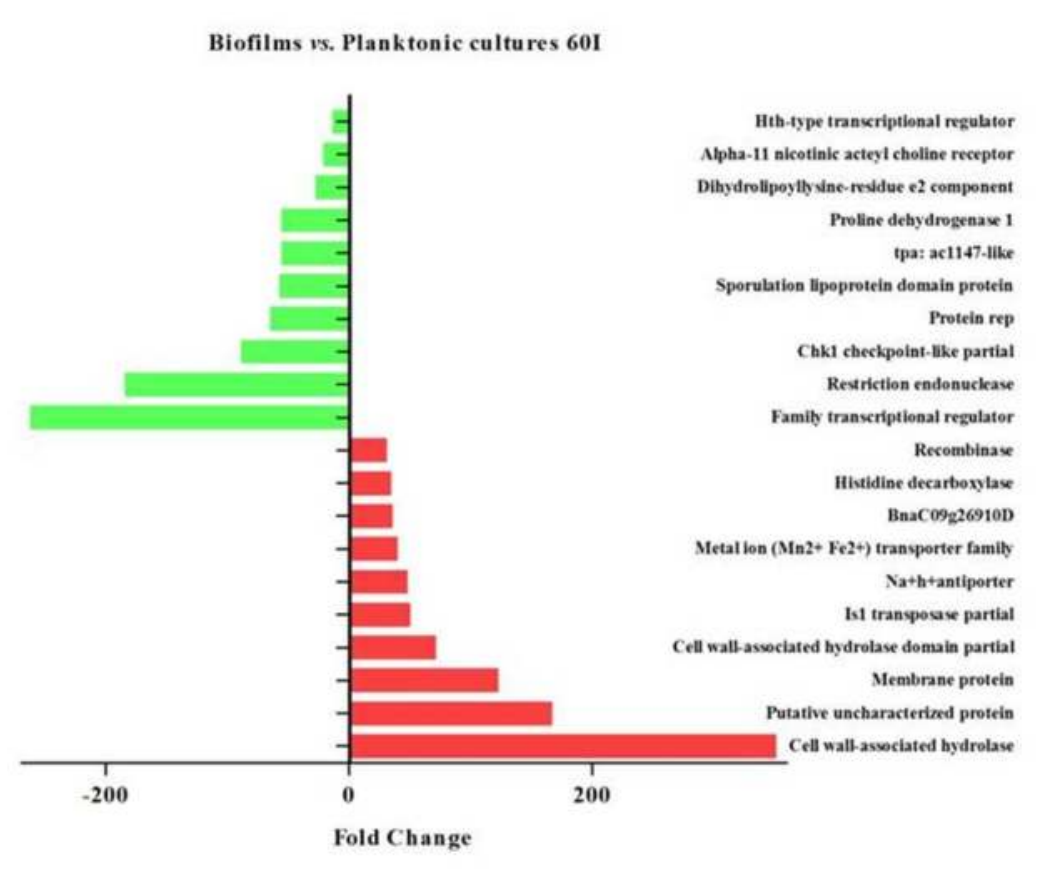

Fig. 3. Fold Change Plot of differentially expressed transcripts in $H$. capsulatum biofilms vs. planktonic cultures, EH-315 (A) and 60 I (B) strain. Representation of 20 transcripts with significant differential expression and functional annotation (Gene Ontology - GO).

\section{CONCLUSION}

In the present study are indicated the molecules (transcripts) that constitute a potential source to delineate: a) a marker of biofilms; b) new prototypes for the therapy of histoplasmosis and; c) new biomarkers as diagnostic tools for histoplasmosis.

\section{REFERENCES}

COSTERTON, J. W. et al. Microbial biofilms. Annu Rev Microbiol, v. 49, p. 711-745, 1995.

PITANGUI, N. S. et al. Adhesion of Histoplasma capsulatum to pneumocytes and biofilm formation on an abiotic surface. Biofouling, v. 28, n. 7, p. 711-718, 2012.

PITANGUI, N. D. S. et al. An Intracellular Arrangement of Histoplasma capsulatum YeastAggregates Generates Nuclear Damage to the Cultured Murine Alveolar Macrophages. Frontiers in Microbiology, v. 6, 1526, 2016.

RODRÍGUEZ-CERDEIRA, C. et al. Systemic Fungal Infections in Patients with human inmunodeficiency virus. Actas Dermosifiliogr, 2012. 